\title{
Impact of Medications on Cognitive Function of Persons with Alzheimer's Disease: A Review for Practitioners
}

\begin{abstract}
Alzheimer's disease is a neurodegenerative condition commonly accompanied by chronic comorbid medical conditions; therefore it is not surprising that patients with Alzheimer's disease regularly take various prescription and over-the-counter drugs. Since most of them are older, they are at greatest risk because of the number of medications, the physiological changes of aging and pathological changes of dementias. As a result, there is a tremendous need for practitioners to pay more attention to neurocognitive effects of drugs in this population. If possible, practitioners should attempt to select drugs that have no or less neurocognitive effects for these patients. One of the strategies can be an active involvement of pharmacists in various clinical settings to meet the special needs of this special population. In this article, the authors reviewed documented cognitive effects of commonly used drugs in various clinical settings, which can adversely affect already decompensated cognitive function of patients with Alzheimer's disease.
\end{abstract}

\section{Introduction}

Alzheimer's Disease (AD), which represents the most common cause of dementing disorders, is expected to impact 13.8 million individuals by 2050 [1]. In fact, a new diagnosis of $\mathrm{AD}$ will be made every 33 seconds by 2050 [2]. Marked by substantial morbidity, loss of independence, healthcare system implications, the predicted $\mathrm{AD}$ associated costs will rise to $\$ 1.2$ trillion by 2050 [3]. Importantly, practitioners play an integral role in prescribing medications for this population, with inappropriate prescribing resulting in advancing rates of hospitalization, morbidity, and mortality [4]. Furthermore, clinical challenges to prescribing practice include polypharmacy, medical comorbidities, adverse drug reactions, age related physiologic changes, and lack of educational training [5-9].

$\mathrm{AD}$ is a gradual, progressive neurodegenerative condition commonly accompanied by chronic medical comorbidities including heart failure, ischemic heart disease, and diabetes [10]. Therefore, it is not surprising that $\mathrm{AD}$ patients regularly take various prescription and over-the-counter drugs. As a result, polypharmacy is frequently observed, which is implicated in advanced risk for adverse drug reactions, inappropriate prescribing, and drug interactions [1113]. However, in reality, the focus must be on the appropriateness, effectiveness, and safety of the drugs in individual patients rather than polypharmacy itself [14]. Furthermore, progressive AD is implicated in deteriorating memory, executive functioning, and other cognitive function, which can lead to medication non-adherence and difficulty communicating concerns with associated provider [15]. Importantly, a recent study revealed that primary care related prescribing errors are highest in patients older than 65 [14]. As a result, practitioners should aim to develop appropriate prescribing habits to limit common, yet
Journal of

Parkinson's disease $\&$ Alzheimer's disease

\author{
Ralph R. McKenzie ${ }^{1}$, Christa A. Witt ${ }^{2}$ and Kye Y. \\ $\mathrm{Kim}^{3^{*}}$ \\ ${ }^{I}$ Carilion Clinic-Virginia Tech Carilion School of Medicine \\ Psychiatry Residency Program, Virginia, USA \\ ${ }^{2}$ Carilion Clinic-Virginia Tech School of Medicine Internal \\ Medicine Residency Program, Virginia, USA \\ ${ }^{3}$ Department of Psychiatry \& Behavioral Medicine, Virginia Tech \\ Carilion School of Medicine and Carilion Clinic Center for Healthy \\ Aging, Virginia, USA
}

\section{*Address for Correspondence}

Kye Y. Kim, Department of Psychiatry \& Behavioral Medicine, Virginia Tech Carilion School of Medicine and Carilion Clinic Center for Healthy Aging, Virginia, USA, Tel: 540-981-7653; Fax: 540-981-7469; E- ail: kykim@carilionclinic.org

Submission: 14 June, 2017

Accepted: 26 June, 2017

Published: 18 July, 2017

Copyright: () 2017 McKenzie, et al. This is an open access article distributed under the Creative Commons Attribution License, which permits unrestricted use, distribution, and reproduction in any medium, provided the original work is properly cited.

preventable medication related adverse events [16]. In this article, the authors reviewed documented cognitive effects of commonly used drugs in various clinical settings, which can adversely affect already decompensated cognitive function of patients with $\mathrm{AD}$ [16].

\section{Factors Causing Adverse Neurocognitive Effects of Drugs}

\section{Aging}

Aging is associated with critical physiologic changes impacting medication prescribing. Specifically, with age related advances in body fat percentage, lipophilic drugs, such as benzodiazepines, often accumulate and can subsequently result in drug related toxicity [17]. In addition, decreasing total body water, reduced lean muscle mass are associated with declining volume of distribution precipitating supratherapeutic plasma levels resulting in adverse drug reactions [18]. Lastly, decrease in brain mass, increasing permeability of the blood brain barrier and decreased cerebral blood flow are implicated in medication sensitivity in older population [19].

\section{Changes in pharmacokinetics and pharmacodynamics}

Additionally with aging, individuals differ both in the way their body handles drugs (pharmacokinetics) and in their responses to drugs (pharmacodynamics). Differences in their inter-individual variability of response may require alterations in the dose or dosing regimen in order to produce the desired results without undue toxicity or adverse effects to the patient. Alterations in drug metabolism are associated with adverse medication side effects in elderly adults. Specifically, the impact of pharmacokinetics, characterized by drug absorption, metabolism, distribution and excretion should impact prescriber habits [19]. For example, medication related side effects are precipitated in malnourished patients by reduced albumin levels, 
Citation: McKenzie RR, Witt CA, Kim KY. Impact of Medications on Cognitive Function of Persons with Alzheimer's Disease: A Review for Practitioners. J Parkinsons Dis Alzheimer Dis. 2017;4(1): 8.

ISSN: $2376-922 X$

Table 1: Medication impact of various drug classes in persons with Alzheimer's disease.

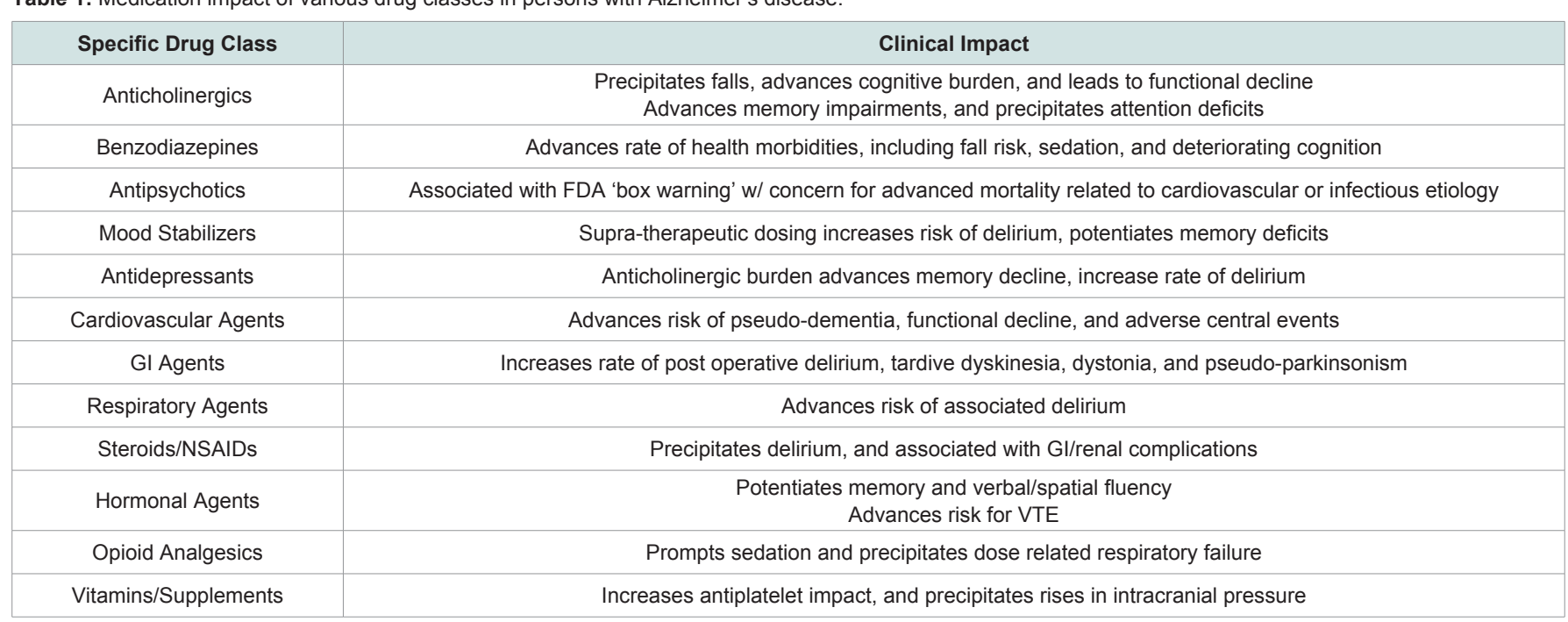

resulting from advance free drug concentrations [20]. Additionally, pharmacodynamics or the bodily response to medications are altered by receptor sensitivities as well as reduced medication clearance [21]. For instance, decreased receptor sensitivity of beta receptors are associated with reduced therapeutic response to beta blockers [22]. Alternatively, increased receptor sensitivity to anticoagulants and calcium channel blockers can lead to medication response at reduced dosing [23]. Understanding the role of renal clearance is critically important for drug-related prescribing in elderly population. In fact, aging is associated with a reduced renal perfusion, resulting in a decreased glomerular filtration rate [24]. Additionally, nonuniform decline in renal plasma flow and associated glomerular filtration rate can have impact on medication dosing [25]. For instance, lethal adverse effects are associated with medications with narrow therapeutic ranges, including lithium, digoxin and associated aminoglycoside antibiotics [25]. Age related hepatic clearance is impacted by reduced hepatic blood flow and decreased hepatic mass [26]. In fact an estimated $30-40 \%$ reduction in perfusion and hepatic mass is anticipated with advancing age [26]. Additionally, phase I oxidative metabolism is compromised in elderly, impacting medications reliant on the oxidative CYP 450 pathway. With reduced first pass metabolism, plasma levels are increased, which can prompt effective medication responses with reduced dosing [27].

\section{Genetic polymorphism}

Genetic variations are implicated in the biotransformation or medication clearance from the body. As a result of sequencing studies, allele variants have been discovered, which involve Phase I oxidative metabolism, specifically CYP 450 2C, 2D6 in addition to Phase II acetylation [28]. In fact, CYP 450 polymorphisms can potentiate drug related side effects. For example, patients who are rapid metabolizers of CYP 2D6, which involves an estimated $5 \%$ of Caucasian population, may precipitate a reduced therapeutic medication response resulting from suboptimal dosing [29]. In contrast, adverse drug reactions often develop at therapeutic dose in individuals such as 2D6 poor metabolizers, particularly with use of antidepressants including tricyclic antidepressants and SSRIs [30].

\section{Identifying and Assessing the Neurocognitive Effects of Drugs}

Approaching medication related side effects in preexisting cognitive impairment represents a significant challenge in clinical practice. Patients may be unaware of any change due to their compromised cognition. Additionally, they may attempt to minimize or deny deterioration in, for instance, memory. Further complicated by limitations in processing speed and working memory, patients with cognitive impairment have reduced rates of medication adherence [31]. Additionally, complex medication regimens as well as the rate of polypharmacy are critical barriers to providing care [32]. Importantly, monitoring for acute drug related mentation changes is often difficult due to inability to establish baseline cognitive functioning. Therefore, provider communication and caregiver involvement are essential to describing recent care, as well as established mentation [33]. Generally, medication related neurocognitive alterations involve the extrapyramidal system, orientation, thoughts, perceptions, memory and executive functioning.

\section{Extrapyramidal functions}

Extrapyramidal symptoms, manifested by acute dystonia, akathisia, parkinsonism and tardive dyskinesia are often embarrassing and potentially disabling medication related side effects critical to prescribing practitioners [34]. Drug-induced extrapyramidal dysfunctions are important because they are typically reversible. Most commonly resulting from exposure to high potency typical antipsychotics or other medications, including calcium channel blockers and antiemetic agents are often implicated in represented movement disorders [34]. Clinically, antipsychotic use to aid in management of neuropsychiatric disturbances of dementia is complicated by the advanced risk of infectious and cardiovascular mortality [35]

\section{Orientation}

Assessment of orientation involves details including person, place, time and situation. An acute, fluctuating mentation, characterized by disorientation, altered consciousness and inability to maintain concentration are precipitated by the risk factor of cognitive 
impairment [36]. Furthermore, medications such as narcotics, benzodiazepines, antihistamines, antispasmodics and antipsychotics are often implicated in drug-induced delirium [37]. Specifically, anticholinergic medication is particularly harmful in dementia patients due to reduced acetylcholine levels [38].

\section{Thoughts and perceptions}

Sudden alterations in perceptions, including the presence of delusions, hallucinations or presence of disorganized thoughts in setting of no previous psychiatric history, should warrant further investigation for underlying medical causes [39]. Also, the patient can often experience psychotic symptoms as a result of medications, most commonly corticosteroids, antiparkinsonian drugs, anticholinergics and antiarrhymics [40].

\section{Memory}

Routine scale administration, notably the MMSE, by the prescribing practitioner is critical to evaluate potential medication induced cognitive deficits, as well as establishing baseline comparison [41]. Although self-report is typically limited, caregiver input can familiarize the practitioner with current cognitive deficits [42]. A sudden deterioration from the baseline may warrant an association with recently started medications.

\section{Executive function}

Executive function refers to the ability to plan, set goals, organize and shift between tasks and to inhibit the tendency to distraction [43]. Particularly critical to medication management, dementia patients often require additional assistance to ensure adherence with a medication regimen [44]. Abnormalities in this CNS function is probably the accumulative effect of derangements in orientation, thoughts, perceptions and memory. Patient may not be aware of the difficulty with executive functions at all. Inquiries to the patient's family and caregiver may eliminate this difficulty.

\section{Effects of Specific Drug Classes}

\section{Anticholinergic agents}

Anticholinergic burden in established cognitive decline can precipitate neurocognitive symptoms, marked by deteriorating memory and altered attention [45]. Influenced by baseline cognition, critical to the development of medication related side effects is the total anticholinergic burden [45]. Impacted by the vast array of medications with anticholinergic load, patients with cognitive decline often develop falls, functional deterioration and deteriorating cognition secondary to medication properties [46]. In fact, a recent study revealed that $10-25 \%$ of dementia patients are currently using or prescribed medications with significant anticholinergic impact [47]. Therefore, the role of the practitioner should be to consider anticholinergic impact of prescribed medications and limit the use in established cognitive impairment [48].

\section{Benzodiazepines}

Benzodiazepine use in dementia patients is implicated in marked functional decline [49]. For instance, benzodiazepine use has been associated with increased rates of hip fractures, gait dysfunction, sedation and falls [49]. Additionally, long-acting benzodiazepines are implicated in development of delirium and worsening cognition [50]. Therefore, according to the 2012 Beers Criteria, practitioners are cautioned against the use of long acting benzodiazepines [51].

\section{Antipsychotics}

Neuropsychiatric symptoms, estimated to occur in $90 \%$ of $\mathrm{AD}$ patients during the disease course, present difficult medication decisions for practitioners [52,53]. Despite the current FDA 'box warning' regarding use of antipsychotics in dementia care, specifically with concern for advanced risk of infectious and cardiovascular mortality, prescribing patterns are relatively stable in the U.S, with nearly $25 \%$ of longitudinal patients in nursing home facilities receiving antipsychotic medications [54,55]. Associated side effects of use include functional decline, increased morbidity and mortality [55]. Particularly, low potency first generation antipsychotics have significant anticholinergic burden, orthostatic hypotension and can deteriorate cognitive functioning [56].

\section{Mood stabilizers}

Cognitive decline associated with anticonvulsant use has involved medications including primidone, phenytoin and Phenobarbital [57]. Advanced risk during use for potentiation of memory deficit and precipitated delirium has been linked to polypharmacy and supratherapeutic dosing [57]. Lastly, valproic acid has rarely has been implicated in potentiating delirium secondary to elevated ammonium [58].

\section{Antidepressants}

Untreated depression in dementia patients is associated with reduced quality of life, declining function and cognitive decline [59]. With coexisting apathy, further complicated by presence of aphasia, dementia patients often underreport depressive symptoms [60]. Treatment of depressive symptoms should aim to limit potential anticholinergic activity, which occurs most commonly with Tricyclic Antidepressants (TCA), notably imipramine and amitriptyline [61]. In contrast, favorable medication profiles exist for sertraline, escitalopram and fluoxetine [61]. Overall, selective serotonin reuptake inhibitors rarely potentiate memory deficits or associated delirium [61].

\section{Antibiotic agents}

Antibiotic agents are often overused in the elderly, particularly in the patients with established cognitive decline. In fact, an estimated $44 \%$ of people in U.S. nursing homes with cognitive impairment received antibiotic treatments, despite minimal clinical criteria warranting treatment [62]. Furthermore, inappropriate antibiotic use is implicated in antimicrobial resistance, advanced treatment burden and reduced quality of life in patients [62]. Specifically, critical side effects, including neurotoxicity and encephalopathy are often associated with beta-lactam antibiotics and fluoroquinolones, complicated by reduced creatinine clearance in setting of altered neuroplasticity of the blood brain barrier [63]. Most commonly occurring to treat asymptomatic bacteriuria, providers are often limited by difficulty in expression of concerning symptoms by patients with advanced dementia [64]. As a result, it is increasingly evident that criteria for prescribing antibiotics be developed to limit unnecessary complications, as well as limit multi-drug resistant 
organisms. Lastly, providers should consider the medication risks and discuss proposed treatments with associated caregiver prior to prescribing in this vulnerable population [64].

\section{Cardiovascular agents}

When treating a patient with cardiovascular agents, it is important to recognize the balance between reducing morbidity and mortality with regards to cerebrovascular and cardiovascular disease with the potentially detrimental effects of these medications on cognitive functioning. Specifically, reduced treatments of associated risk factors, including diabetes and hypertension can potentiate small vessel ischemia resulting in vascular dementia [65]. Among beneficial cardiovascular medications are ACE inhibitors, which are thought to reduce levels of angiotensin II, a potentiator of many inflammatory mediators. ACE inhibitors have also been shown to decrease mortality in congestive heart failure and improve insulin signaling in diabetes [66]. Additionally, a UK sub-study of the Study on Cognition and Prognosis in the Elderly (SCOPE) trial reported that treatment with an angiotensin receptor blocker reduced cognitive decline [67]. It is also important to remember to strike a balance between hypotension through overtreatment and hypertension, which can lead to cerebrovascular disease. Cardiovascular medications also have many neurocognitive effects. For example, even some individual patients studied with reduced doses of beta-blockers have shown to be at increased risk for pseudo-dementia [68]. Beta blockers are commonly used to decrease morbidity and mortality in regards to cardiovascular events and in congestive heart failure. However, it was shown in one study that elderly patients in nursing homes over 65 years of age prescribed beta-blockers had more functional decline in those with underlying cognitive impairment after MI, even while they still had mortality benefit [69]. Newer studies are suggesting that even in those patients without dementia, learning was shown to be slowed with administration of beta 1 selective blockers [70]. In fact, a large crosssectional study in elderly treated with anti-hypertensive conducted in France suggests better cognitive functioning in those individuals receiving calcium channel blocking agents [71]. Alpha blockers, clonidine, methyldopa have all been shown to cause adverse central events, in addition to additional impact of urinary incontinence and bradycardia in the elderly. Alternatives to these include thiazides, ACEIs or calcium channel blockers [72].

According to the CDC, atrial fibrillation is the most common heart arrhythmia that is diagnosed. Its incidence is increasingly common in elderly populations, as are the medications that are used to treat it. It is also well established that people with atrial fibrillation are at increased risk for ischemic stroke [73]. However, the medications that are used to treat atrial fibrillation are not without their risks to the elderly in terms of cognitive effects and toxicity. Digoxin toxicity, as an example, is associated with CNS symptoms. In fact, even with normal digoxin levels, cognitive function may be affected and may be the only presenting feature in elderly populations. It has been suggested that due to decreased renal clearance in elderly persons, the maximum dose should be about $125 \mathrm{mcg}$ per day [73]. In addition, other antiarrhythmics, including procainamide, amiodarone, quinidine, lidocaine and disopyramide have been associated with delirium [74].

There has been a long debate in recent years regarding the effects of statins on memory and cognition among prescribers. There is conflicting evidence regarding statins and effects on memory [75]. Many experimental studies have shown that cholesterol intake increases amyloid synthesis. Observational studies suggest a reduced risk of dementia in those taking statins. However, despite these promising findings, many prospective studies show no cognitive benefits for patients taking statins. There are also case reports that may suggest an association with cognitive impairment and statin dosing [75].

\section{Gastrointestinal agents}

Anticholinergic effects of anti-emetics have been shown to contribute to mild cognitive impairment in elderly adults, particularly with promethazine, metoclopramide and prochlorperazine. Serious CNS effects, including dystonia, pseudo-parkinsonism and tardive dyskinesia have been reported [76]. Persistent delirium associated with loperamide use has been documented [77]. In contrast, ondansetron has been suggested to improve cases of post-operative delirium in elderly orthopedic patients [78].

\section{Respiratory agents}

Current data is limited on the impact of inhaled corticosteroids on cognition. Specifically, a single case report demonstrated that butesonide-formoterol can precipitate delirium [79]. Azithromycin, on the other hand, is a commonly prescribed antibiotic for both acute treatment of community acquired pneumonia, bronchitis/ COPD exacerbations and is even prescribed chronically for its anti-inflammatory properties by some pulmonologists. It has been associated with cases of delirium in elderly populations, particularly related to the extended half-life [80].

\section{Steroids and NSAIDs}

Steroids are the mainstay of treatment for many inflammatory conditions, including rheumatologic disease, inflammatory bowel disease and COPD exacerbations. The medication impact, which appears to be dose dependent on neurocognitive function, has been well described in many studies [81]. Even intra-articular steroid injections can precipitate delirium in case reports [82]. Specific to the treatment of inflammatory bowel disease, budesonide has decreased systemic absorption improving side effect profile in elderly [83]. The susceptibility of elderly populations to GI and renal dysfunction with NSAIDs has been well established. However, the effects of NSAIDs on cognition in the elderly are not well described [84].

\section{Hormonal agents}

Testosterone supplementation in elderly males has largely been avoided due to concerns with it increasing PSA levels and prostate cancers, representing a contraindication to starting supplementation. However, several studies have suggested testosterone as being neuroprotective in the aging male [85]. The estrogen/androgen combination supplementation may have a protective effect on memory and improve spatial and verbal fluency in post-menopausal women, although risk of venous thromboembolisms should be considered [86].

\section{Opioid analgesics}

Delirium is well known to be associated with opioids. It is probably 
Citation: McKenzie RR, Witt CA, Kim KY. Impact of Medications on Cognitive Function of Persons with Alzheimer's Disease: A Review for Practitioners. J Parkinsons Dis Alzheimer Dis. 2017;4(1): 8.

caused by the sedative activity of opioids and other toxic effects on the CNS $[87,88]$. In addition, they are highly associated with respiratory failure at elevated dosages. If at all possible, the dosage of opiate agents should be decreased over time in the aged population. Among the opioids, meperidine seems to be the most deliriogenic agent, possibly because of the long half-life and anticholinergic activity of its active metabolite [89].

\section{Vitamins and supplements}

There are many effects of vitamins and supplements with regards to drug interactions and toxicities. Many vitamins and supplements are not monitored and so definitive concentrations cannot be ascertained from dose to dose or brand to brand. However, because of recent surge of the public's interest in vitamins, clinicians should pay attention to their neurotoxic effects. High doses of vitamin A, a fat soluble, may accumulate and can be associated with the syndrome of increased intracranial pressure (Pseudotumor cerebri) [90,91]. Ginkgo biloba has been studied and is one of the more common supplements used specifically for memory enhancement. However, studies have shown that it may increase the effects of antiplatelet agents. Although not statistically significant, in the Gingko Evaluation of Memory (GEM) study comparing ginkgo biloba with antiplatelet agents, there were twice as many hemorrhagic strokes in the treatment group. Unfortunately, for most of the studies involving ginkgo biloba, fatty acids, vitamin B and vitamin E, results were inconclusive with regards to improvement or there were no significant differences found in the groups studied [92].

\section{Strategies to Improve Drug-Induced Neurocognitive Effects}

Prescribing in the elderly population is increasingly difficult secondary to lack of evidence based, validated guidelines of appropriate prescribing [93]. Previously, the medication appropriateness index has been noted to assist prescribers in detecting medication errors, but is frequently time-consuming during routine patient visits [94]. Additionally, the Beer's criteria, for in which it is estimated that $40 \%$ of elderly are prescribed an inappropriate medication, is limited predictive validity with regard to patient outcome data $[95,96]$. Therefore, clinically useful prescribing guidelines are limited in current literature.

\section{Role of Pharmacist}

Pharmacists play in interval role in aiding appropriate prescribing in the dementia population. Specifically, pharmacy should aim to conduct medication reviews, as well as serve as a resource to assess clinicians with treatment decisions [97]. Additionally, pharmacists are interval to educating patients regarding medication administration, communications side effects, and ensuring understanding of drug regimen [98]. Furthermore, provider should incorporate pharmacists as essential treatment team members in an effort to promote patient satisfaction and treatment outcomes [99].

\section{Role of Practitioner}

Practitioners often are presented with challenges to prescribing in elderly patients including polypharmacy, medication interactions, lack of associated guidelines and medication non-adherence [100]. In the cognitively impaired, reporting of associated adverse side effects is limited. Therefore, provider should aim to involve caregivers to discuss treatment goals, as well as evaluate continued use of medications prescribed, as a way to reduce associated treatment burden [101]. In additional challenge to prescribers exists in adjusting treatment goals in the setting of end-of-life care decisions. Specifically clinical vignettes have shown to be a useful venue of clinical education [102]. It is critical that the prescriber be aware of existing prescribing guidelines and make use of continuing medical education [103]. Furthermore, prescriber should aim to reduce medication frequency of dosing, provide medication instructions and aim to simplify medication regimen. Lastly, the provider should target the lowest effective medication dose, avoid medications with extended half-lives and consider the efficacy of medication use related to potential for adverse drug reaction [104]. Inappropriate medication prescribing in dementia patients has been associated with increased health care utilization and advancing risk of morbidity and mortality [105]. With the aging population, the practitioner will face challenging clinical decisions with regard to caring for the cognitively impaired. Furthermore, proposing cognitive engagement in physical activity and associated brain exercises could help to decreased risk of developing dementia [106]. Lastly, further guidelines aiding in appropriate prescribing in the dementia population is critical to optimizing health related outcomes in this vulnerable population.

\section{Conclusion}

Patients with $\mathrm{AD}$ or other dementias are especially vulnerable to medication-related problems. Since most of them are older, they are at greatest risk because of the number of medications they take, the physiological changes of aging and pathological changes of dementias. Therefore, there is a tremendous need for practitioners to pay more attention to neurocognitive effects of drugs in this population. If possible, practitioners should attempt to select drugs that have no or less neurocognitive effects for these patients. Also, it is important to recognize the neurocognitive effects early on and develop reasonable strategies to reduce or eliminate them. One of the strategies can be an active involvement of pharmacists in various clinical settings to meet the special needs of this special population.

\section{References}

1. (2017) Statistics. Alzheimer's Association home page.

2. (2017) Physician and healthcare professionals: General statistics/ demographics. Alzheimer's Association home page.

3. (2014) Alzheimer's and related dementia fact sheet. Patients and caregivers American Association for Geriatric Psychiatry home page.

4. Maher RL, Hanlon J, Hajjar ER (2013) Clinical consequences of polypharmacy in elderly. Expert Opin Drug Saf 13: 57-65.

5. Patterson SM, Cadogan CA, Kerse N, Cardwell CR, Bradley MC, et al. (2014) Interventions to improve the appropriate use of polypharmacy for older people. Cochrane Database Syst Rev.

6. Viktil KK, Blix HS, Moger TA, Reikvam A (2007) Polypharmacy as commonly defined is an indicator of limited value in the assessment of drug-related problems. Br J Clin Pharmacol 63: 187-195.

7. O'Mahony D, Gallagher PF (2008) Inappropriate prescribing in the older population: Need for new criteria. Age Ageing 37: 138-141.

8. Beynon CM (2008) Drug use and ageing: Older people do take drugs. Age Ageing 38: 8-10.

9. Imfeld P, Brauchli Pernus YB, Jick SS, Meier CR (2013) Epidemiology, co-morbidities, and medication use of patients with Alzheimer's disease or 
Citation: McKenzie RR, Witt CA, Kim KY. Impact of Medications on Cognitive Function of Persons with Alzheimer's Disease: A Review for Practitioners. J Parkinsons Dis Alzheimer Dis. 2017;4(1): 8.

vascular dementia in the UK. J Alzheimers Dis 35: $565-573$

10. Arrighi HM, Neumann PJ, Lieberburg IM, Townsend RJ (2010) Lethality of Alzheimer disease and its impact on nursing home placement. Alzheimer Dis Assoc Disord 24: 90-95.

11. Lavan AH, Gallagher PF, O'Mahony D (2016) Methods to reduce prescribing errors in elderly patients with multimorbidity. Clin Interv Aging 11: 857-866

12. Steinman MA, Landefeld CS, Rosenthal GE, Berthenthal D, Sen S, et al (2006) Polypharmacy and prescribing quality in older people. J Am Geriatr Soc 54: 1516-1523.

13. Goldberg RM, Mabee J, Chan L, Wong S (1996) Drug-drug and drug-disease interactions in the ED: Analysis of a high-risk population. Am J Emerg Med 14: $447-450$

14. Kathleen C, Anne Werner R (2000) A guide to medication and aging Generations 14: 8-21.

15. Elliott AR, Goeman D, Beanland C, Koch S (2015) Ability of older people with dementia or cognitive impairment to manage medicine regimens: A narrative review. Curr Clin Pharmacol 10: 213-221.

16. Arlt S, Lindner R, Rosler A, Renteln-Kruse WV (2008) Adherence to medication in patients with dementia: Predictors and strategies for improvement. Drugs Aging 25: 2033-1047.

17. Corsonello A, Pedone C, Incalzi RA (2010) Age-related pharmacokinetic and pharmacodynamic changes and related risk of adverse drug reactions. Curr Med Chem 17: 571-584.

18. Swift CG (2003) The clinical pharmacology of ageing. Br J Clin Pharmaco 56: $249-253$.

19. Jacobson SA (2015) Clinical manual of geriatric psychopharmacology, $\left(2^{\text {nd }} e d n\right)$. American Psychiatric Publishing, Washington DC, pp. 1-239.

20. Mangoni AA, Jackson SH (2003) Age-related changes in pharmacokinetics and pharmacodynamics: Basic principles and practical applications. $\mathrm{Br} \mathrm{J}$ Clin Pharmacol 57: 6-14

21. Khan LM (2013) Comparative epidemiology of hospital-acquired adverse drug reactions in adults and children and their impact on cost and hospital stay-A systematic review. Eur J Clin Pharmacol 69: 1985-1996.

22. O'Malley K1, Docherty JR, Kelly JG (1988) Adrenoreceptor status and cardiovascular function in ageing. J Hyper 6(Suppl.1): S59-S62.

23. Brenes-Salazar JA, Alshawabkeh L, Schmade KE, Hanlon JT, Forman DE (2015) Clinical pharmacology relevant to older adults with cardiovascular disease. J Geriatr Cardiol 12: 192-195.

24. Corsonello A, Pedone C, Corica F, Mussi C, Carbonin P, et al. (2005) Concealed renal insufficiency and adverse drug reactions in elderly hospitalized patients. Arch Intern Med 165: 790-795.

25. Popa MA (2007) Age-related changes in pharmacokinetics and pharmacodynamics. In: Markides KS (Ed), Encyclopedia of Health \& Aging SAGE Publications, Inc, USA, pp. 680.

26. Gallagher P, Barry P, O'Mahony D (2007) Inappropriate prescribing in the elderly. J Clin Pharm Ther 32: 113-121.

27. Shi S, Klotz U (2011) Age-related changes in pharmacokinetics. Curr Drug Metab 12: 601-610.

28. Crews KR, Gaedigk A, Dunnenberger HM, Klein TE, Shen DD, et al. (2011) Clinical Pharmacogenetics Implementation Consortium (CPIC) guidelines for codeine therapy in the context of cytochrome P450 2D6 (CYP2D6) genotype. Clin Pharmacol Ther 91: 321-326.

29. Horvitz-Lennon M, Mattke S, Predmore Z, Howes OD (2017) The role of antipsychotic plasma levels in the treatment of schizophrenia. Am J Psychiatry 174: 421-426.

30. Bertilsson L, Dahl ML, Dalen P, Al-Shurbaju A (2002) Molecular genetics of CYP2D6: Clinical relevance with focus on psychotropic drugs. $\mathrm{Br} \mathrm{J}$ Clin Pharmacol 53: 111-122.

31. Kronish IM, Diefenbach MA, Edmondson DE, Phillips LA, Fei K, et al. (2013)
Key barriers to medication adherence in survivors of strokes and transient ischemic attacks. J Gen Intern Med 28: 675-682.

32. Osterberg L, Blaschke T (2005) Adherence to medication. N Engl J Med 353: 487-497.

33. Kaasalainen S, Dolovich L, Papaioannou A, Holbrook A, Lau E, et al. (2011) The process of medication management for older adults with dementia. $J$ Nurs Healthc Chronic IIIn 3: 407-418.

34. Dalaya P, Chou KL (2008) Antipsychotic-induced extrapyramidal symptoms and their management. Expert Opin Pharmacother 9: 1451-1462.

35. Siarkos KT, Katirtzoglou EA, Politis AM (2015) A review of pharmacological treatments for depression in alzheimer's disease. J Alzheimers Dis 48: 15-34.

36. O'Keeffe S, Lavan JN (1999) Clinical significance of delirium subtypes in older people. Age Ageing 28: 115-119.

37. Mate KE, Kerr KP, Pond D, Williams EJ, Marley J, et al. (2015) Impact on multiple low-level anticholinergic medications on anticholinergic load of community-dwelling elderly with and without dementia. Drugs Aging 32: 159167.

38. Sura SD, Carnahan RM, Chen H, Aparasu RR (2013) Prevalence and determinants of anticholinergic medication use in elderly dementia patients. Drugs Aging 30: 837-844

39. Bell JS, Mezrani C, Blacker N, LeBlanc T, Frank O, et al. (2012) Anticholinergic and sedative medicines: prescribing considerations for people with dementia. Aust Fam Physician 41: 45-49.

40. Inouye SK, Charpentier PA (1996) Precipitating factors for delirium in hospitalized elderly persons. Predictive model and interrelationship with baseline vulnerability. JAMA 275: 852-857.

41. Elliott RA, Marriott JL (2010) Review of instruments used in clinical practice to assess patients' ability to manage medications. J Pharm Pract Res 40: 36-42.

42. Allaire JC, Gamaldo A, Ayotte BJ, Sims R, Whitfield K (2009) Mild cognitive impairment and objective instrumental everyday functioning: The everyday cognition battery memory test. J Am Geriatr Soc 57: 120-125.

43. Hodges JR (2001) Early-onset dementia: A multidisciplinary approach Oxford University Press, USA, pp. 477.

44. While C, Duane F, Beanland C, Koch S (2012) Medication management: The perspectives of people with dementia and family carers. Dementia 12: 734750 .

45. Flacker JM, Cummings V, Mach JR, Bettin K, Kiely DK, et al. (1998) The association of serum anticholinergic activity with delirium in elderly medical patients. Am J Geriatr Psychiatry 6: 31-41.

46. Lowry E, Woodman RJ, Soiza RL, Mangoni AA (2011) Associations between the anticholinergic risk scale score and physical function: Potential implications for adverse outcomes in older hospitalized patients. J Am Med Dir Assoc 12: 565-572.

47. Bhattacharya R, Chatterjee S, Carnahan RM, Aparasu RR (2011) Prevalence and predictors of anticholinergic agents in elderly outpatients with dementia. Am J Geriatr Pharmacother 9: 434-441.

48. Palmer JB, Albrecht JS, Park Y, Dutcher S, Rattinger GB, et al. (2015) Use of drugs with anticholinergic properties among nursing home residents with dementia: A national analysis of medicare beneficiaries 2007-2008. Drugs Aging 32: 79-86.

49. Ried LD, Johnson RE, Gettman DA (1998) Benzodiazepine exposure and functional status in older people. J Am Geriatr Soc 46: 71-76.

50. Cumming RG, Le Couteur DG (2003) Benzodiazepines and risk of hip fractures in older people: a review of the evidence. CNS Drugs 17: 825-837.

51. Moore AR, O'Keeffe ST (1999) Drug-induced cognitive impairement in the elderly. Drugs Aging 15: 15-28.

52. Greenblatt HK, Greenblatt DJ (2016) Use of antipsychotics for the treatment of behavioral symptoms of dementia. J Clin Pharmacol 56: 1048-1057.

53. Spek KV, Gerritsen DL, Smalbrugge M, Nelissen-Vrancken MH, Wetzels RB, 
Citation: McKenzie RR, Witt CA, Kim KY. Impact of Medications on Cognitive Function of Persons with Alzheimer's Disease: A Review for Practitioners. J Parkinsons Dis Alzheimer Dis. 2017;4(1): 8.

et al. (2015) A reliable and valid index was developed to measure appropriate psychotropic drug use in dementia. J Clin Epidemiol 68: 903-912.

54. FDA (2017) Postmarket drug safety information for patients and providers: Information on conventional antipsychotics. Drug Saf Availability.

55. Foebel AD, Onder G, Finne-Soveri H, Lukas A, Denkinger MD, et al. (2016) Physical restraints and antipsychotic medication use among nursing home residents with dementia. J Am Med Dir Assoc 17: e9-e14.

56. Caligiuri MP, Lacro JP, Jeste DV (1999) Incidence and predictors of druginduced parkinsonism in older psychiatric patients treated with very low doses of neuroleptics. J Clin Psychopharmacol 19: 322-328.

57. Aldenkamp AP, Vermeulen J (1995) Phenytoin and carbamazepine: Differential effects on cognitive function. Seizure 4: 95-104

58. Ruuskanen I, Kilpelainen HO, Riekkinen PJ (1979) Side effects of sodium valproate during long-term treatment in epilepsy. Acta Neurol Scand 60: 125128

59. Marano C, Lyketsos CG (2016) Pharmacologic treatments for neuropsychiatric symptoms. In: Rabins PV, Lyketsos CG, Steele CD (Eds), Practical Dementia Care, ( $3^{\text {rd }}$ edn). Oxford University Press, USA, pp. 384

60. Jesús PE, José Luis TG, Carlos RB (2011) Depression in patients with moderate Alzheimer disease: A prospective observational cohort study. Alzheimer Dis Assoc Disord 25: 317-325.

61. Jacobson SA (2014) Clinical manual of geriatric psychopharmacology, $\left(2^{\text {nd }} e d n\right)$. American Psychiatric Publishing, Washington DC, pp. 536.

62. D'Agata E, Mitchell SL (2008) Patterns of antimicrobial use among nursing home residents with advanced dementia. Arch Intern Med 168: 357-362.

63. Parsons C (2017) Polypharmacy and inappropriate medication use in patients with dementia: An underresearched problem. Ther Adv Drug Saf 8: 31-46.

64. Alagiakrishnan K, Wiens CA (2004) An approach to drug induced delirium in the elderly. Postgrad Med J 80: 388-393.

65. Munzel T, Gori T, Bruno RM, Taddei S (2010) Is oxidative stress a therapeutic target in cardiovascular disease? Eur Heart J 31: 2741-2748.

66. Sukhanov S, Yoshida T, Tabony AM, Higashi Y, Galvez S, et al. (2011) Angiotensin II, oxidative stress and skeletal muscle wasting. Am J Med Sci 342: 143-147.

67. Hansson L (2000) Study on cognition and prognosis in the elderly (Scope) Evaluation of risk factors: P2.36. J Hypertens 18: S98.

68. (2007) Cognitive impairment associated with depression in the elderly. J Clin Psychiatry 68: 1601-1612.

69. Beta-blockers risk functional decline in some older patients (2017) Pharm J.

70. Burkauskas J, Noreikaite A, Bunevicius A, Brozaitiene J, Neverauskas J, et al. (2016) Beta-1-selective beta-blockers and cognitive functions in patients with coronary artery disease: A cross-sectional study. J Neuropsychiatry Clin Neurosci 28: 143-146.

71. Hanon O, Berrou JP, Negre-Pages L, Goch JH, Nadhazi Z, et al. (2008) Effects of hypertension therapy based on eprosartan on systolic arterial blood pressure and cognitive function: Primary results of the observational study on cognitive function and systolic blood pressure reduction open-label study. $J$ Hypertens 26: 1642-1650.

72. Potentially inappropriate drugs are commonly prescribed for elderly outpatients. PsycEXTRA Dataset.

73. Toxic neuropsychiatric effects of digoxin at therapeutic serum concentrations (2006) Am J Psychiatry 144: 506-507.

74. Hui DS, Morley JE, Mikolacjczak PC, Lee R (2015) Atrial fibrillation: A major risk factor for cognitive decline. Am Heart J 169: 448-456.

75. Wagstaff LR, Mitton MW, Arvik BM, Doraiswamy PM (2003) Statin-associated memory loss: Analysis of 60 case reports and review of the literature. Pharmacotherapy 23: 871-780.

76. Lee MSS, Hanger HC (2017) Audit of anticholinergic medication changes in older hospitalised patients using the anticholinergic drug scale. Intern Med $\mathrm{J}$ 47: 689-694

77. Schwartz RH, Rodriguez WJ (1991) Toxic delirium possibly caused by loperamide. J Pediatr 118: 656-657.

78. Papadopoulos G, Pouangare G, Papathanakos G, Amaoutoglou E, Petrou A, et al. (2014) The effect of ondansetron on postoperative delirium and cognitive function in aged orthopedic patients. Minerva Anestesiol 80: 444451.

79. Moss JM, Kemp DW, Brown JN (2014) Combination of inhaled corticosteroid and bronchodilator-induced delirium in an elderly patient with lung disease. J Pharm Pract 27.

80. Cone LA, Padilla L, Potts BE (2003) Delirium in the elderly resulting from azithromycin therapy. Surg Neurol 59: 509-511.

81. Aronson JK (2016) Meyler's side effects of drugs, (16 ${ }^{\text {th }}$ edn): The international encyclopedia of adverse drug reactions and interactions. Elsevier Sci, UK, pp. 7674.

82. Lally L, Mccarthy G, Meehan K (2017) Hyperactive delirium following administration of intra-articular corticosteroids. BMJ Case Rep.

83. Kim M, Katz S, Green J (2015) Drug management in the elderly IBD patient. Curr Treat Options Gastroenterol 13: 90-104

84. Cunningham C, Skelly DT (2012) Non-steroidal anti-inflammatory drugs and cognitive function: Are prostaglandins at the heart of cognitive impairement in dementia and delirium? J Neuroimmune Pharmacol 7: 60-73.

85. Giagulli VA, Guastamacchia E, Licchelli B, Triggiani V (2016) Serum testosterone and cognitive function in ageing male: Updating the evidence. Recent Pat Endocr Metab Immune Drug Discov 10: 22-30.

86. Wisniewski AB, Nguyen TT, Dobs AS (2002) Evaluation of high-dose estrogen and high-dose estrogen plus methyltestosterone treatment on cognitive task performance in postmenopausal women. Horm Res Paediatr 58: 150-155.

87. Stiefel F, Morant R (1991) Morphine intoxification during acute reversible renal insufficiency. J Palliat Care 7: 45-47.

88. Marcantonio ER, Juarez G, Goldman L, Mangione CM, Ludwig LE, et al. (1994) The relationship of postoperative delirium with psychoactive medications. JAMA 272: 1518-1522.

89. Miller R, Jick H (1978) Clinical effects of opioids in cancer patients. J Clin Pharmacol 18: 180-189.

90. Restak RM (1972) Pseudotumor cerebri, psychosis, and hypervitaminosis A. J Nerv Ment Dis 155: 72-75.

91. Morrice G, Havener WH, Kapetansky F (1960) Vitamin A intoxication as a cause of pseudotumor cerebri. JAMA. 173: 1802-1805.

92. Gestuvo MK, Hung WW (2012) Common dietary supplements for cognitive health. Aging Health 8: 89-97.

93. Jano E, Aparasu RR (2007) Healthcare outcomes associated with Beers' Criteria: A systematic review. Ann Pharmacother 41: 438-447.

94. Hanlon JT, Schmader KE (2013) The medication appropriateness index at 20: Where it started, where it has been, and where it may be going. Drugs Aging 30: 893-900.

95. Curtis LH, Ostbye T, Sendersky V, Hutchinson S, Dans PE, et al. (2004) Inappropriate prescribing for elderly americans in a large outpatient population. Arch Intern Med 164: 1621-1625.

96. Beers MH, Ouslander JG, Rollingher I, Reuben DB, Brooks J, et al. (1991) Explicit criteria for determining inappropriate medication use in nursing home residents. UCLA division of geriatric medicine. Arch Intern Med 151: 18251832.

97. Aparasu RR, Mort JR (2004) Prevalence, correlates and associated outcomes of potentially inappropriate psychotropic use in the community dwelling elderly. Am J Geriatr Pharmacother 2: 102-111.

98. Field TS, Gurwitz JH, Harrold LR, Rothschild J, Debellis KR, et al. (2004) Risk factors for adverse drug events among older adults in the ambulatory setting. 
Citation: McKenzie RR, Witt CA, Kim KY. Impact of Medications on Cognitive Function of Persons with Alzheimer's Disease: A Review for Practitioners. J Parkinsons Dis Alzheimer Dis. 2017;4(1): 8.

J Am Geriatr Soc 52: 1349-1354.

99. Kripalani S, Lefevre F, Phillips CO, Williams MV, Basaviah P, et al. (2007) Deficits in communication and information transfer between hospital-based and primary care physicians: Implications for patient safety and continuity of care. JAMA 297: 831-841.

100.Lui GG, Christensen DB (2002) The continuing challenge of inappropriate prescribing in the elderly: An update of the evidence. J Am Pharm Assoc 42: 847-857.

101. Macrum ZA, Hanlon JT (2013) Inappropriate medication use and medication errors in the elderly. In: Wehling $M(E d)$, Drug therapy for the elderly. Springer, Germany, pp. 43-50.
102. Peabody JW, Luck J, Glassman P, Jain S, Hansen J, et al. (2004) Measuring the quality of physician practice by using clinical vignettes: A prospective validation study. Ann Intern Med 141: 771-780.

103. Mort JR, Aparasu RR (2002) Prescribing of psychotropics in the elderly: Why is it so often inappropriate? CNS Drugs 16: 99-109.

104. Kaasalainen S, Dolovich L, Papaioannou A, Holbrook A, Lau E, et al. (2011) The process of medication management for older adults with dementia. $J$ Nurs Healthc Chronic IIIn 3: 407-418.

105. Shamliyan T (2010) Adverse drug effects in hospitalized elderly: Data from the healthcare cost and utilization project. Clin Pharmacol 2: 41-63.

106. Hogervorst E, Clifford A, Stock J, Xin X, Bandelow S (2012) Exercise to prevent cognitive decline and Alzheimer's disease: For whom, when, what, and (most importantly) how much? J Alzheimers Dis Parkinsonism 2: e117. 